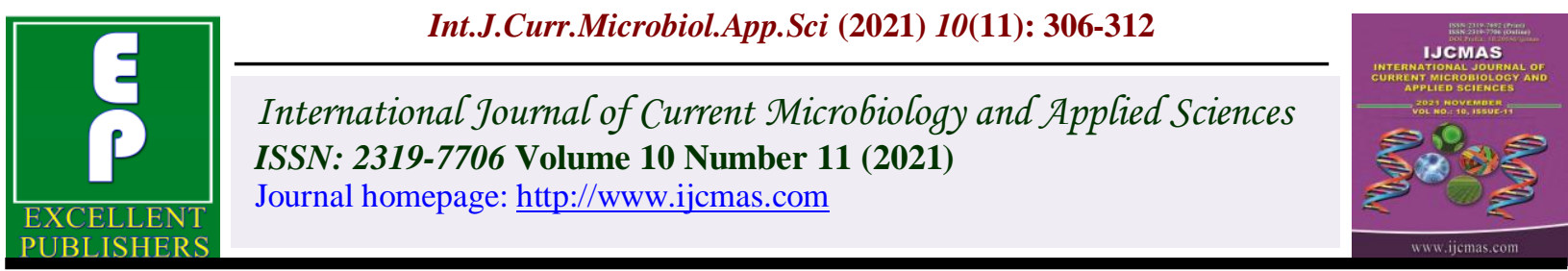

\title{
Microbiological Profile of Uropathogens and their Antibiotic Susceptibility Pattern in Pediatric Population from a Tertiary Care Hospital in Amritsar, Punjab
}

\author{
Manpreet Kaur Bhathal*, Loveena Oberoi, Sapna Soneja, \\ Anuradha Malhotra and Kamaldeep Singh
}

Department of Microbiology, GMC Amritsar, India

*Corresponding author

\section{A B S T R A C T}

\section{Keywords}

Urinary tract infections, uropathogens, antimicrobial resistance

\section{Article Info}

Received:

10 October 2021

Accepted:

05 November 2021

Available Online:

10 November 2021
Aims and objective of the study: Urinary tract infection(UTI) is one of the most commonest bacterial infection encountered in the pediatric age group. Early diagnosis is of utmost importance to preserve renal function and reduce long term complications such as renal scarring. The objective of this study was to determine the prevalence of UTI in pediatric population, identify the common uropathogens and study the antibiotic susceptibility pattern of bacterial isolates. Materials and Methods: A retrospective study was carried out in Department of Microbiology, GMC Amritsar for a period of 6 months from 1 Jan 2021 till 30 June 2021 amongst the pediatric patients (1 month-12 years age group) with clinically suspected UTI including both indoor and outdoor patients. Clean catch midstream urine samples received in the laboratory were processed as per the standard microbiological guidelines. Antibiotic susceptibility testing was done using Kirby-Bauer disc diffusion method as per CLSI guidelines. Results: A total of 549 samples were received and processed during study period from which $164(29.87 \%)$ were culture positive. Culture positivity was more prevalent in females $(61.58 \%)$ than males $(38.41 \%)$. Gram negative organisms were predominant (74.4\%) followed by gram positive cocci $(22.56 \%)$ and Candida (3.05\%). Among gram negative organisms Escherichia coli was most predominant followed by Klebsiella spp., Pseudomonas spp., Acinetobacter spp., Proteus spp. and Citrobacter spp. Among gram positive cocci Staphylococcus aureus was most predominant followed by Coagulase negative Staphylococci and Enterococcus spp. Majority of gram negative bacilli were resistant to fluroquinolones, $3^{\text {rd }}$ generation cephalosporins and co-trimoxazole while nitrofurantoin, piperacillin-tazobactam and gentamicin were most sensitive drugs. Among Staphylococcus aureus, methicillin resistance was seen in $17 \%$ isolates. High sensitivity was seen to linezolid and vancomycin in gram positive cocci. Conclusion: This study highlights increased prevalence of MDR uropathogens in pediatric population which indicates that antibiotic selection should be based on knowledge of local prevalence of bacterial organisms and their antibiotic sensitivities with rational use of antibiotics. 


\section{Introduction}

Urinary tract infection is one of the most common pediatric infections. It distresses the child, concerns the parents, and may cause permanent kidney damage. The infection may affect the upper urinary tract (referred to as pyelonephritis) or the lower urinary tract (referred to as cystitis). Up to $8 \%$ of children will experience at least one UTI between ages of 1 month and 11 years ${ }^{(1,2)}$ and up to $30 \%$ of infants and children experience recurrent infections during the first 6 to 12 months after initial UTI. ${ }^{(3,4)}$

The clinical presentation of UTI in infants and young children may vary from undiagnosed fever to gastrointestinal manifestations as well as upper and lower urinary tract symptoms whereas, in older children symptoms referring to the urinary tract may be observed ${ }^{(5)}$.

UTI in paediatric age group is different in all the way from adults mainly by following congenital abnormalities of urinary tract namely post urethral valves, pelvic-ureteric junction obstruction, neurogenic bladder, stricture urethra, vesicoureteral reflux which is very true in infants. ${ }^{(6)}$

UTI is often difficult to diagnose in paediatric population because of the minimal and vague non specific signs and symptoms. It is more important to diagnose the condition timely and accurately as it may itself can lead to significant morbidity from renal scarring, hypertension and eventually end-stage renal disease. In community and hospital settings the aetiology of UTIs and antimicrobial susceptibility pattern of uropathogens have been changing over the years. ${ }^{(7)}$

Gram negative enteric bacilli, especially Escherichia coli and Klebsiella spp. are the leading pathogens though Enterococcus spp., yeasts and Staphylococcus aureus have emerged as prominent agents in recent years, many of them resistant to multiple antibiotics ${ }^{(8-10)}$. The emergence of antibiotic resistant uropathogens in paediatric urology is increasing worldwide; particularly in developing countries where empirical treatment is the mainstay of treatment in the absence of proper diagnostic modalities and the availability of antibiotics over the counter $^{(11,12)}$. An updated knowledge regarding antimicrobial resistance pattern in a specific location may aid clinicians in choosing the appropriate antibiotic for empirical treatment.

The study was conducted to know the prevalence of uropathogens and their antibiotic susceptibility pattern in paediatric patients. This information could help the clinicians in timely diagnosis and proper antibiotic selection.

\section{Materials and Methods}

A retrospective study was carried out in Department of Microbiology, GMC Amritsar for a period of 6 months from 1 Jan 2021 till 30 June 2021.Pediatric patients of age group 1 year-12 year attending OPD/IPD and presenting with signs/symptoms of UTI were included in the study. A total of 549 midstream clean catch urine samples in sterile universal containers were received in the department during the study period. Urine samples were processed within 2 hour of collection and in case of delay, the sample were refrigerated at $2-8{ }^{\circ} \mathrm{C}$.

\section{Sample processing}

A calibrated loop method (semi quantitative method) was used for the isolation of pathogens from urine samples. A loopful urine sample was plated on Mac-Conkey agar \& Blood agar and the inoculated plates were incubated at $37^{\circ} \mathrm{C}$ for $18-24$ hours. Significant 
isolates were identified by conventional methods according to the standard microbiology guidelines, including colony morphology, gram staining and biochemical reactions ${ }^{(13)}$.

\section{Antimicrobial susceptibility testing}

The antibiotic sensitivity test was performed by Kirby Bauer disc diffusion method by using commercially available Hi-Media antibiotic discs on Mueller Hinton agar plates. Antibiotics that were tested in our study included: ampicillin, amoxycillin-clavulanate, gentamicin, co-trimoxazole, nitrofurantoin, norfloxacin, ceftriaxone, cefepime, piperacillin-tazobactam, sulbactamceftriaxone, meropenem, imipenem, vancomycin and linezolid. Interpretation of antibiotic susceptibility results were made as per zone size interpretative standards of CLSI guidelines $^{(14)}$.

\section{Results and Discussion}

A total of 549 samples were received from children with suspected UTI during the study period among which $313(57.01 \%)$ samples were from female patients and 236 (42.98\%) samples from male patients. Culture positivity was seen in 164 (29.87\%) samples, out of which 101(61.58\%) were females and 63(38.41\%) were males as shown in Table1.

Gram negative organisms (74.4\%) were the most predominant organisms accounting for $122(74.4 \%)$ isolates, followed by gram positive cocci $37(22.56 \%)$ and 5 Candida $(3.05 \%)$ isolates. Among the gram negative isolates, Escherichia coli was the most predominant $(\mathrm{n}=72,59.01 \%)$ followed by Klebsiella pneumoniae $(\mathrm{n}=24, \quad 19.7 \%)$, Pseudomonas aeruginosa $(\mathrm{n}=9, \quad 7.37 \%)$, Klebsiella oxytoca $\quad(\mathrm{n}=6, \quad 4.91 \%)$,
Acinetobacter baumanii ( $\mathrm{n}=6, \quad 4.91 \%)$, Proteus mirablis $(\mathrm{n}=4, \quad 3.27 \%)$ and Citrobacter freundi $(\mathrm{n}=1,0.82 \%)$. Among gram positive cocci Staphylococcus aureus was most predominant $(\mathrm{n}=18, \quad 48.64 \%)$ followed by Coagulase negative Staphylococci $\quad(\mathrm{n}=14, \quad 37.83 \%) \quad$ and Enterococcus spp. $(\mathrm{n}=5,13.51 \%)$. Distribution of same is described in figure 1 and 2.

Majority of gram negative bacilli were resistant to norfloxacin $(78.7 \%)$, ceftriaxone (72.9\%) and co-trimoxazole(47.54\%), while nitrofurantoin $(78.7 \%)$, piperacillintazobactam $(74.6 \%)$ and gentamicin $(70.5 \%)$ were most sensitive drugs.

Among Staphylococcus aureus, methicillin resistance was seen in 3 isolates $(8.10 \%)$. Maximum sensitivity was seen to Linezolid(100\%) and vancomycin (100\%) amongst gram positive cocci. Resistance to ampicillin (90.2\%) and norfloxacin (77.1\%) was seen in both gram positive and gram negative isolates.

UTI in paediatric age group is common and significant source of morbidity and mortality. The prevalence of paediatric UTI differs with age, gender and certain predisposing factors like underlying systemic illness, structural and functional abnormalities of urinary tract like posterior urethral valves, pelviureteric junction obstruction, neurogenic bladder and vesico-ureteric reflex ${ }^{(15)}$.

The prevalence of culture proven UTI among children in our study was found to be $29.87 \%$. The findings of this study was concordant with studies conducted by Taneja et al., $(28.3 \%)^{(15)}$, Badhan et al., $(26.7 \%)^{(16)}$, in Northern India. The rate is higher than study done by Khandelwal and Sutariya et al., $(9.91 \%)^{(6)}$ and Mohanty et al.,(14.7\% $)^{(17)}$. 
Table.1 Distribution of gender wise Culture Positive samples

\begin{tabular}{|c|c|c|}
\hline Gender & Significant growth(n=164) & $\begin{array}{c}\text { No growth/Insignificant } \\
\text { growth(n=385) }\end{array}$ \\
\hline Female $(\mathbf{n = 3 1 3 )}$ & $101(61.58 \%)$ & $212(67.7 \%)$ \\
\hline Male $(\mathbf{n = 2 3 6})$ & $63(38.41 \%)$ & $173(73.3 \%)$ \\
\hline Total = 549 & $164(29.87 \%)$ & $385(70.12 \%)$ \\
\hline
\end{tabular}

Table.2 Antibiotic susceptibility pattern of gram negative urinary isolates

\begin{tabular}{|c|c|c|c|c|c|c|}
\hline \multirow{2}{*}{ Antibiotics } & \multicolumn{5}{|c|}{ \% isolates resistant to antibiotic } \\
\cline { 2 - 6 } & $\begin{array}{c}\text { E.coli } \\
(\mathrm{n}=72)\end{array}$ & $\begin{array}{c}\text { Klebsiella } \\
\text { spp.(n=30) }\end{array}$ & $\begin{array}{c}\text { Pseudomonas } \\
\text { spp.(n=9) }\end{array}$ & $\begin{array}{c}\text { Acinetobacter } \\
\text { spp.(n=6) }\end{array}$ & $\begin{array}{c}\text { Proteus } \\
\text { spp.(n=4) }\end{array}$ & $\begin{array}{c}\text { Citrobacter } \\
\text { spp.(n=1) }\end{array}$ \\
\hline Ampicillin & $\begin{array}{c}68 \\
(94.4 \%)\end{array}$ & $30(100 \%)$ & $9(100 \%)$ & $5(83.3 \%)$ & $4(100 \%)$ & $1(100 \%)$ \\
\hline Amoxicillin-clavunate & $46(63.8 \%)$ & $21(70 \%)$ & $9(100 \%)$ & $4(66.7 \%)$ & $3(75 \%)$ & $1(100 \%)$ \\
\hline Ceftriaxone & $52(72.2 \%)$ & $21(70 \%)$ & $9(100 \%)$ & $4(66.7 \%)$ & $3(75 \%)$ & $0(0 \%)$ \\
\hline Ceftriaxone/sulbactam & $28(38.9 \%)$ & $11(36.7 \%)$ & $9(100 \%)$ & $3(50 \%)$ & $1(25 \%)$ & $0(0 \%)$ \\
\hline Cotrimoxazole & $24(33.3 \%)$ & $18(60 \%)$ & $9(100 \%)$ & $2(33.3 \%)$ & $4(100 \%)$ & $1(100 \%)$ \\
\hline Nitrofurantoin & $13(18.1 \%)$ & $9(30 \%)$ & $4(44.4 \%)$ & $0(0 \%)$ & $0(0 \%)$ & $0(0 \%)$ \\
\hline Norfloxacin & $62(86.1 \%)$ & $21(70 \%)$ & $4(44.4 \%)$ & $4(66.7 \%)$ & $4(100 \%)$ & $1(100 \%)$ \\
\hline Gentamicin & $24(33.3 \%)$ & $9(30 \%)$ & $2(22.2 \%)$ & $1(16.7 \%)$ & $0(0 \%)$ & $0(0 \%)$ \\
\hline $\begin{array}{c}\text { Piperacillin- } \\
\text { tazobactam }\end{array}$ & $17(13.5 \%)$ & $9(30 \%)$ & $2(22.2 \%)$ & $2(33.3 \%)$ & $1(25 \%)$ & $0(0 \%)$ \\
\hline
\end{tabular}

Table.3 Antibiotic susceptibility pattern of gram positive urinary isolates

\begin{tabular}{|c|c|c|c|}
\hline \multirow{2}{*}{ Antibiotics } & \multicolumn{3}{|c|}{$\%$ of isolates resistant to antibiotic } \\
\cline { 2 - 4 } & S. aureus $(\mathrm{n}=18)$ & CONS $(\mathrm{n}=14)$ & $\begin{array}{c}\text { Enterococcus spp } \\
(\mathrm{n}=5)\end{array}$ \\
\hline Ampicillin & $14(77.8 \%)$ & $12(85.7 \%)$ & $5(100 \%)$ \\
\hline Cefoxitin & $3(16.7 \%)$ & $0(0 \%)$ & - \\
\hline Gentamicin & $1(5.6 \%)$ & $7(50 \%)$ & $3(60 \%)$ \\
\hline Nitrofurantoin & $1(5.6 \%)$ & $0(0 \%)$ & $2(40 \%)$ \\
\hline Norfloxacin & $14(77.8 \%)$ & $12(85.7 \%)$ & $5(100 \%)$ \\
\hline Tetracycline & $5(27.8 \%)$ & $5(35.7 \%)$ & $2(40 \%)$ \\
\hline Cotrimoxazole & $11(61.1 \%)$ & $11(78.6 \%)$ & - \\
\hline Linezolid & $0(0 \%)$ & $0(0 \%)$ & $0(0 \%)$ \\
\hline Vancomycin & $0(0 \%)$ & $0(0 \%)$ & $0(0 \%)$ \\
\hline
\end{tabular}


Fig.1

Figure 1. Distribution of gram negative urinary isolates

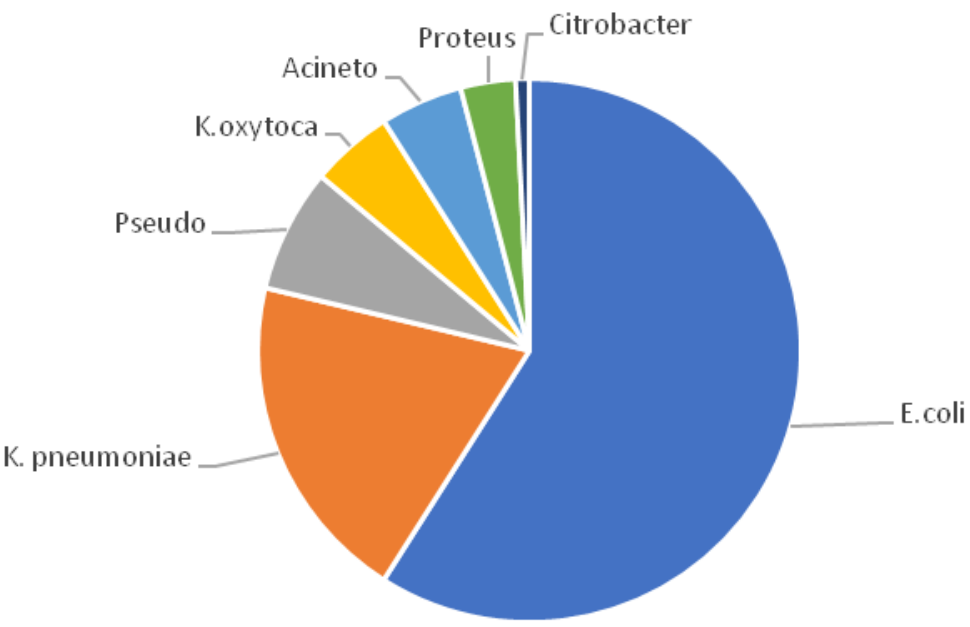

- E.coli - K. pneumoniae $\square$ Pseudo $=$ K.oxytoca $\|$ Acineto $\square$ Proteus - Citrobacter

Fig.2

Figure 2. Distribution of gram positive urinary isolates

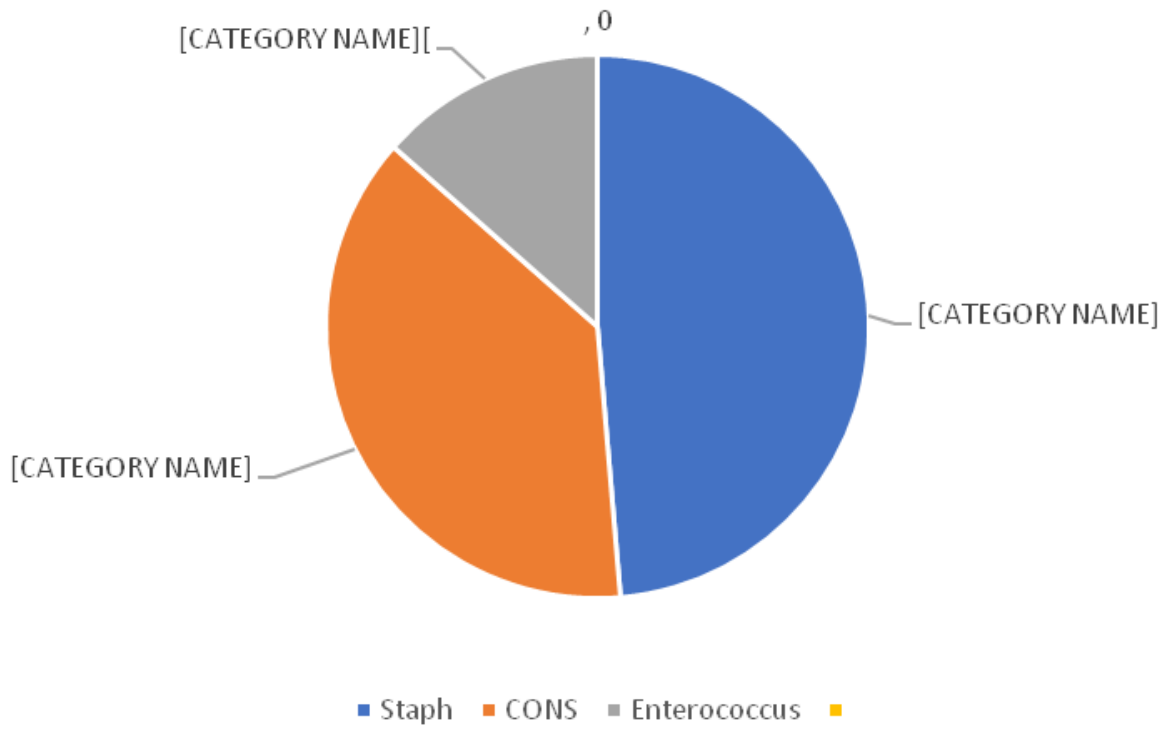

The present study showed higher incidence of UTI in females(61.58\%) than males $(38.41 \%)$ which was consistent with study conducted by
Badhan et al., ${ }^{(16)}$ and Akram et al., ${ }^{(18)}$. The higher incidence in females might be due to presence of shorter urethra and the proximity 
of reproductive organs close to anus, also higher number of samples received from females in our study.

Out of 159 bacterial isolate, majority of the isolates were gram negative with preponderance of Escherichia coli, Klebsiella pneumoniae and Pseudomonas aeruginosa. Among gram positive cocci Staphylococcus aureus was most predominant followed by Coagulase negative Staphylococci and Enterococcus spp. The pattern and the frequency of bacterial isolates obtained in this study were comparable with different studies conducted in India ${ }^{(16,19)}$.

Uropathogens are showing increasing trend of antimicrobial resistance worldwide which can be explained by the fact that drugs are available over the counter especially in developing countries where prescription is not monitored. Significant degree of antibiotic resistance was observed among the uropathogens.

In our study low susceptibility of gram negative organisms was observed to first line drugs like fluoroquinolones and cotrimoxazoles which are commonly used oral antibiotics for treatment of UTI in our population. These findings were in concordance with study done by Kalantar et al., ${ }^{(20)}$. The most active antibiotics against gram negative pathogens were nitrofurantoin and gentamicin which correlates with Rajabhandari et al., ${ }^{(21)}$. Maximum resistance to ampicillin (83.78\%), norfloxacin $(83.78 \%$ ) and co-trimoxazole $(59.45 \%)$ was seen amongst gram positive cocci with 3 MRSA isolates were obtained. The possible reason for high drug resistance might be due to empirical consumption of the antibiotics without culture sensitivity testing in our region.

Antimicrobial resistance pattern in uropathogens of paediatric patients indicates that antibiotic selection should be based on the local prevalence of organisms and their antimicrobial susceptibility pattern rather than empirical treatment.

Important facts emanating from the present study include:

Girls were more commonly affected

Empirical treatment with cotrimoxazoles and fluoroquinolones might be insufficient due to increased resistance of $E$. coli and other uropathogens though initially they were the drugs of choice for UTIs

Nitrofurantoin and gentamicin could be used as therapeutic alternatives in uncomplicated cases of paediatric UTI and piperacillintazobactam in those with severe UTI.

This study along with previous studies indicate the need for periodic monitoring of uropathogens and development of protocols for the rational use of antibiotics

\section{References}

1. Hoberman A, Chao H-P, Keller D M, Hickey R, Davis H W, Ellis D. Prevalence of urinary tract infection in febrile infants. J Pediatr. 1993 Jul 1;123(1):17-23.

2. Mårild S, Jodal U. Incidence rate of first-time symptomatic urinary tract infection in children under 6 years of age. Acta Paediatr. 1998;87(5):549-52.

3. Mangiarotti P, Pizzini C, Fanos V. Antibiotic Prophylaxis in Children with Relapsing Urinary Tract Infections: Review. J Chemother. 2000 Jan 1;12(2):115-23.

4. Nuutinen $M$, Uhari $M$. Recurrence and follow-up after urinary tract infection under the age of 1 year. Pediatr Nephrol. 2001 Jan 1;16(1):69-72.

5. Bonkat G, Pickard R, Bartoletti R, Bruyère F, Geerlings SE, Wagenlehner F, et al., EAU guidelines on urological infections. Eur Assoc Urol. 2017;22-6. 
6. Khandelwal N, Sutariya D. Retrospective study of bacteriological profile and their antibiotic sensitivity pattern in urine of pediatric patients $(0-12$ years) in a tertiary care hospital of South Gujarat. Indian $\mathbf{J}$ Microbiol Res. 2020 Dec 15;7(4):373-6.

7. Neu H C. Urinary tract infections. Am J Med. 1992 Apr 6;92(4A):63S-70S.

8. Narasimhan K L, Mahajan J K, Kaur B, Mittal B R, Bhattacharya A. The vesicoureteral reflux dysplasia syndrome in patients with posterior urethral valves. J Urol. 2005 Oct 1;174(4 Part 1):1433-5.

9. Chandrasekharam V, Srinivas M, Charles A, Agarwala S, Mitra D, Bal C, et al., Urinarytract infection affects somatic growth in unilateral symptomatic hydronephrosis. Pediatr Surg Int. 2002 Jul 1;18(5):451-4.

10. Narasimhan K L, Chowdhary S K, Kaur B, Mittal B R, Bhattacharya A. Factors affecting renal scarring in posterior urethral valves. J Pediatr Urol. 2006 Dec 1;2(6):569-74.

11. Bryce A, Hay A D, Lane I F, Thornton H V, Wootton M, Costelloe C. Global prevalence of antibiotic resistance in paediatric urinary tract infections caused by Escherichia coli and association with routine use of antibiotics in primary care: systematic review and metaanalysis. BMJ. 2016 Mar 15;352:i939.

12. Edlin R S, Copp H L. Antibiotic resistance in pediatric urology. Ther Adv Urol. 2014 Apr $1 ; 6(2): 54-61$.

13. Collee J G, Mackie T J, McCartney J E. Mackie \& McCartney practical medical microbiology. Harcourt Health Sciences; 1996.

14. M100Ed31 Performance Standards for Antimicrobial Susceptibility Testing, 31st Edition [Internet]. Clinical \& Laboratory Standards Institute. [cited 2021 Sep 19].
Available from: https://clsi.org/standards/products/microbiolog $\mathrm{y} /$ documents $/ \mathrm{m} 100 /$

15. Taneja N, Chatterjee S S, Singh M, Singh S, Sharma M. Pediatric urinary tract infections in a tertiary care center from north India. Indian J Med Res. 2010 Jan 1;131(1):101-6.

16. Badhan R, Singh D V, Badhan L R, Kaur A. Evaluation of bacteriological profile and antibiotic sensitivity patterns in children with urinary tract infection: A prospective study from a tertiary care center. Indian J Urol IJU J Urol Soc India. 2016;32(1):50-6.

17. Mohanty S, Kapil A, Das B K, Dhawan B. Antimicrobial resistance profile of nosocomial uropathogens in a tertiary care hospital. Indian J Med Sci. 2003 Apr;57(4):148-54.

18. Akram M, Shahid M, Khan A U. Etiology and antibiotic resistance patterns of communityacquired urinary tract infections in $\mathrm{J} \mathrm{N} \mathrm{M} \mathrm{C}$ Hospital Aligarh, India. Ann Clin Microbiol Antimicrob. 2007 Mar 23;6:4.

19. Tryphena C, Sahni R D, John S, Jeyapaul S, George A, Helan J. A retrospective study on the microbial spectrum and antibiogram of uropathogens in children in a secondary care hospital in Rural Vellore, South India. J Fam Med Prim Care. 2021 Apr;10(4):1706-11.

20. E.a K, M.e M, H L, N R. Prevalence of Urinary Tract Pathogens and Antimicrobial Susceptibility Patterns In Children At Hospitals In Iran. 2008 Jan 1;3(3):149-53.

21. Rajbhandari R, Shrestha J. Bacteriological study of urinary tract infection and its antibiotic sensitivity test: a hospital based study. J Nepal Assoc Med Lab Sci. 2002;4(4):26-32.

\section{How to cite this article:}

Manpreet Kaur Bhathal, Loveena Oberoi, Sapna Soneja, Anuradha Malhotra and Kamaldeep Singh. 2021. Microbiological Profile of Uropathogens and their Antibiotic Susceptibility Pattern in Pediatric Population from A Tertiary Care Hospital in Amritsar, Punjab. Int.J.Curr.Microbiol.App.Sci. 10(11): 306-312. doi: https://doi.org/10.20546/ijcmas.2021.1011.034 